\title{
Co-Infection of Malaria and Hepatitis B Virus in Port Harcourt, Rivers
}

\section{State, Nigeria}

\author{
Austin E Abah $\mathbb{D}^{1,{ }^{*}}$ and Idara N Udoidang ${ }^{1}$ \\ ${ }^{1}$ Department of Animal and Environmental Biology, University of Port Harcourt , Port Harcourt, Nigeria \\ "Corresponding author: Department of Animal and Environmental Biology, University of Port Harcourt, Port Harcourt, Nigeria. Email: austin.abah@uniport.edu.ng
}

Received 2019 August 09; Revised 2019 September 28; Accepted 2019 October 05.

\begin{abstract}
Background: Malaria and hepatitis B virus (HBV) are two diseases of major medical importance in Nigeria.

Methods: The study determined the preponderance of malaria, HBV and their co-infection among 600 outpatients of three major hospitals in Port Harcourt, Nigeria, using standard microscopic method and rapid serology assay diagnostic kit.

Results: Total preponderance rate of malaria, HBV, and co-infection was observed to be $41.0 \%, 6.0 \%$, and $4.33 \%$, respectively. The female gender was more infected with malaria (44.67\%) than the male counterparts (37.54\%), while the males were more infected with $\operatorname{HBV}(7.12 \%)$ and co-infection (5.18\%) than the females with $4.8 \%$ and $3.44 \%$, respectively. The infection rate between genders was not statistically significant $(\mathrm{P}>0.05)$. The prevalence of malaria was statistically high among the age group of 21 - 30 years (55.66\%) $(\mathrm{P}<0.05)$. HBV and co-infection prevalence rate was statistically the highest among the age group of 21 - 30 years with $11.76 \%$ and $10.3 \%$ rates of infection, respectively.

Conclusions: The high rate of malaria prevalence and the presence of HBV and co-infection among the study subjects imply that these infections are threats to the human health and strategies should be adopted to help combat and control these infections.
\end{abstract}

Keywords: Preponderance, Co-Infection, Malaria, Hepatitis B

\section{Background}

Co-infection is the process in which a host becomes infected with multiple pathogen species simultaneously (1). Co-infection is of a vital health significance since there is an interaction and interface of the pathogen species within the host. An example is the co-infection of the hepatitis B virus (HBV) and malaria parasite.

The malaria infection continues to be the most extensive protozoan infection, which affects people. The WHO classified malaria as a worldwide infection that causes numerous mortalities as well as morbidity globally (2). There had been a continuous upsurge in malaria cases and incidences worldwide, particularly in the Sub-Saharan Africa region. Thus, malaria makes up a greater percentage of visits to outpatient units of most hospitals in Nigeria and other nations of the world where there is an endemicity of this deadly disease (3).

Hepatitis B is a major universal and global health issue putting the population at a great danger of death from liver disease (cirrhosis) and liver cancer. According to the World Health Organization document of 2002, the Western Pacific Region as well as the African Region carries the larger percentage of HBV prevalence, where 6.2\% and 6.1\% of the adult populace is living with the infection (4).

Malaria and hepatitis B co-infections pose a great, hazardous, and serious health issue in under developed nations such as Nigeria. These infections are prevalent in most tropical and Sub-Saharan African nations and are both major threats to preventive medicine (5). Coinfection between malaria and HBV can prevail in areas and regions where either infection is prevalent or endemic as a result of their existence in the same geographical area (6). Both diseases have sessions of high activity in the hepatocytic cells and their consequences on the erythrocytes (red blood cells) may result to a suppressed immunity in an individual, making them susceptible to other infections; this will also lead to increased mortality and morbidity (5). Co-infections of malaria and HBV have been reported in Brazilian Amazon, Kano, Ilorin, and Makurdi, respectively (5-8).

\section{Objectives}

There is paucity of reports on the co-infection of both malaria and hepatitis B virus in the oil rich south-south re-

Copyright @ 2019, International Journal of Infection. This is an open-access article distributed under the terms of the Creative Commons Attribution-NonCommercial 4.0 International License (http://creativecommons.org/licenses/by-nc/4.0/) which permits copy and redistribute the material just in noncommercial usages, provided the original work is properly cited. 
gion of Nigeria and this study was aimed at determining the co-infection of malaria and hepatitis B virus in Port Harcourt, Rivers State, Nigeria.

\section{Methods}

\subsection{Study Design}

The study was a descriptive yet cross-sectional study, undertaken between the months of July and December 2018, among subjects (patients) attending the general outpatient unit of three selected Hospitals in Port Harcourt, which included Obio Cottage Hospital, Braithwaite Memorial Specialist Hospital (BMSH), and military hospital (MH).

\subsubsection{Study Area}

This research study was undertaken in Port Harcourt, which is the capital and largest city in Rivers State, located within the south-south geopolitical zone of Nigeria. Its geographical coordinates are 4047'21" North and 6059'55" East (Figure 1). In the year 2016, the city Port Harcourt, which comprises of two local government areas (Port Harcourt and Obio-Akpor), had an estimated population of about 1865000 residents, which is higher than the 1382592 recorded in 2006 conducted population census, which indicates that the city is undergoing a consistent population growth (9). Three major hospitals geographically and spatially located in the city were used as sampling sites. Obio Cottage Hospital is situated in Obio-Akpor L.G.A. while the other sampling hospitals; Braithwaite Memorial Specialist Hospital (BMSH) and military hospital (MH) are both situated in the indigenously dominated Port Harcourt L.G.A. Port Harcourt is a major petroleum industrial center and locations of many multinational firms as well as other local and indigenous industries. The city is located in the tropical rain forest, hence it experiences typically tropical wet climate characterized by long raining and heavy seasons almost throughout the year followed by very short dry seasons experienced between December and January. The city experiences a fairly constant temperature, with very little changes and alteration throughout the year. Average temperature ranges between $25^{\circ} \mathrm{C}-28^{\circ} \mathrm{C}$ in the mega oil rich city.

\subsubsection{Study Populations}

The study was conducted using a total of 600 (309 males and 291 females) adults in the age group 15 to 70 years comprising of 200 outpatients from each of the selected hospitals located in different parts of Port Harcourt.

\subsubsection{Inclusion Criteria}

Six hundred (600) informed female and male patients within the age range of 15 to 70 years who accepted and as well gave their consent by endorsing the consent form were recruited and included in this research.

\subsubsection{Exclusion Criteria}

Other patients who had other confirmed ailments aside malaria and HBV were excluded from this study. Those also undergoing chemotherapy were out right excluded to avoid bias in the gathered sampling data.

\subsection{Ethical Consideration and Informed Consent}

Before starting this research work, approval was sought and gotten from the Research Ethics Committee of the University of Port Harcourt to carry out this work. The managements of each sampling hospitals gave permissions for sample collection and a consent letter was administered to each of the participating subjects after clearly informing them about the objectives as well as the aim of the research. They were also informed of their right to participate or withdraw from the research before, during, and even after the research with no consequence. They were also educated of the confidentiality of the results of the research study.

\subsection{Sample Collection}

Five milliliter of blood was collected via venipuncture with the help and assistance of the laboratory personnel using the vacutainer needle. The blood collected was placed in ethylene diamine tetra-acetic acid (EDTA) bottles and were immediately transported to the parasitology laboratory, within the Department of Animal and Environmental Biology complex; University of Port Harcourt for parasitological as well as serological analysis and examinations.

\subsubsection{Parasitological Examination}

Malaria parasite diagnosis was done using the giemsa stain microscopic screening as described by Cheesbrough (11).

\subsubsection{Hepatitis B Test}

Hepatitis B virus infection diagnosis were done by allowing the blood in the EDTA bottles settle and the plasma were carefully collected and used for the detection of hepatitis B antigen. The antigen was detected with rapid serology assay diagnostic kit as described by Blumberg et al. (12). 


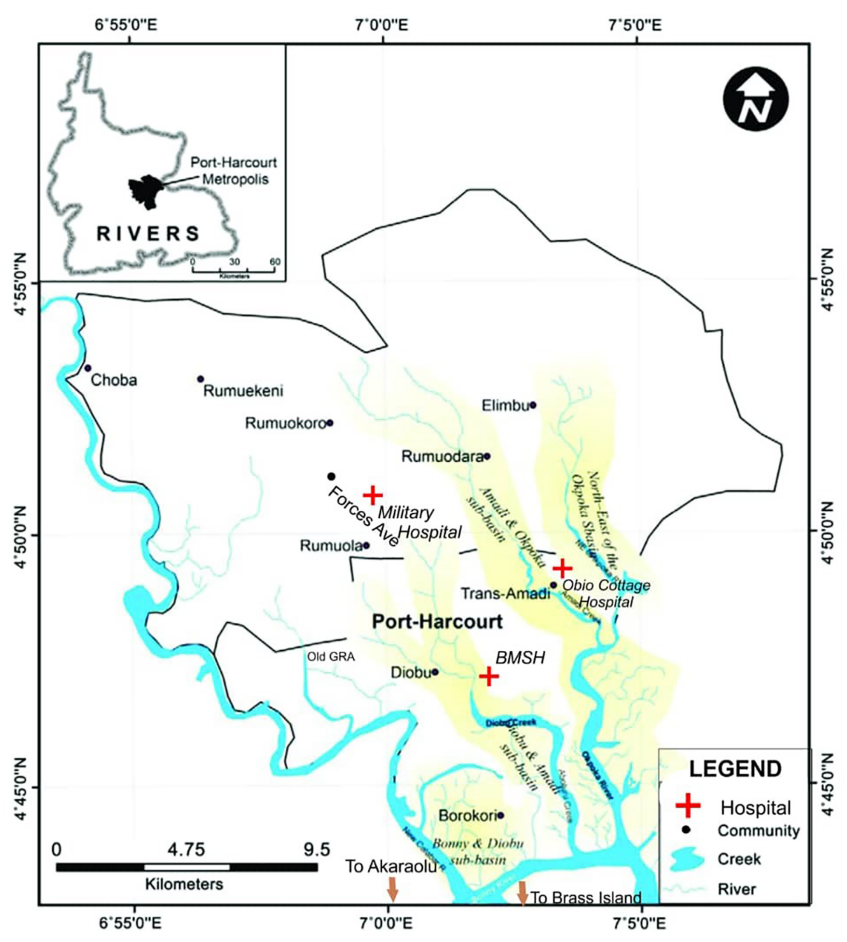

Figure 1. Port Harcourt showing study area and sampling locations, Ebong (10)

\subsection{Analysis of Data}

Data obtained from the diagnosis were analyzed using SPSS software version 21 for both the descriptive as well as the inferential analysis. Results of the analysis were expressed in percentages and the chi-square test was used to conclude the significance levels between the parameters, with the significant value set at 0.05 or $5 \%$.

\section{Results}

\subsection{Malaria Preponderance}

Age and sex malaria prevalence analysis indicates that 246 , which represent $41.0 \%$ of the entire sampled patients, were infected and positive for malaria (Table 1). The female gender recorded a higher malaria prevalence with 130 (44.67\%) compared to the males with 116 (37.54\%). However, with $\mathrm{p}=0.076$, it showed that there was no significant difference in the infection rate between the two genders. The 21 - 30 year age group recorded the highest infection rate with $55.66 \%$, this was fairly followed by the $\leq 20$ years' age group with 40 (43.47\%) prevalence. The $41-50$ years and 51 - 70 years age groups recorded the least infections with 38 (31.93\%) and 39 (33.5\%) prevalence, respectively. With a P $=0.001(\mathrm{P}<0.05)$, there was a significant different between the age groups. In the study, P. falciparum was the only identified malaria species.

\subsection{Hepatitis B Preponderance}

A total of 36 individuals (6.0\%) were found positive for the hepatitis B antigen (HBsAg) as shown in Table 2. Analysis also showed that the HBV Infection was higher among the male gender with 22 (7.12\%) infection rates than the females with 14 (4.8\%). The infection rate between the sexes was not statistically significant with $\mathrm{P}=0.234(\mathrm{P}>$ 0.05). The 21-30-year age group had the highest infection rate with 16 (11.76\%) followed by 31 - 40 years' age group with 9 (6.04\%) infection rate. The least amount of infection was detected among the $51-70$ year age group and 41 - 50 year with 1 (0.96\%) and 2 (1.68\%) infection rate, respectively. There was a significant difference with the P value of $0.001(\mathrm{P}<0.05)$ in the infection rate among the different age groups.

\subsection{Co-Infection of Malaria and Hepatitis $B$}

Of the sampled population, 26 (4.33\%) were detected to have co-infection of the two diseases (malaria and hepatitis B) (Table 3). In addition, the male gender had a greater rate of co-infection of 16 (5.18\%) compared to their female counterparts with 10 (3.44\%), however with $\mathrm{P}=0.295(\mathrm{P}>0.05)$, 


\begin{tabular}{|c|c|c|c|c|c|c|}
\hline \multirow{2}{*}{ Age, $y$} & \multicolumn{2}{|c|}{ Males } & \multicolumn{2}{|c|}{ Females } & \multicolumn{2}{|c|}{ Total } \\
\hline & Examined & Infected & Examined & Infected & Examined & Infected \\
\hline$\leq \mathbf{2 0}$ & $36(6.0)$ & $14(38.89)$ & $56(9.33)$ & $26(46.42)$ & $92(15.33)$ & $40(43.47)$ \\
\hline 21-30 & $58(9.67)$ & $28(48.28)$ & $78(13.0)$ & $48(61.53)$ & $136(22.67)$ & $76(55.88)$ \\
\hline $31-40$ & $78(13.0)$ & $27(34.61)$ & $71(11.83)$ & $26(36.61)$ & $149(24.83)$ & $53(35.57)$ \\
\hline $41-50$ & $62(10.33)$ & $19(30.64)$ & $57(9.5)$ & $19(33.33)$ & $119(19.83)$ & 38 (31.93) \\
\hline$\geq 51$ & $75(12.5)$ & $28(37.33)$ & $29(4.83)$ & $11(37.93)$ & $104(17.33)$ & 39 (33.5) \\
\hline Total & $309(51.5)$ & $116(37.54)$ & $291(48.50)$ & $130(44.67)$ & $600(100.0)$ & $246(41.0)$ \\
\hline
\end{tabular}

${ }^{\mathrm{a}}$ Values are expressed as No. (\%).

Table 2. HBsAg Assessment Based on Age and Sex in Port Harcourt ${ }^{\mathrm{a}}$

\begin{tabular}{|c|c|c|c|c|c|c|}
\hline \multirow{2}{*}{ Age, $y$} & \multicolumn{2}{|c|}{ Males } & \multicolumn{2}{|c|}{ Females } & \multicolumn{2}{|c|}{ Total } \\
\hline & Examined & Infected & Examined & Infected & Examined & Infected \\
\hline$\leq \mathbf{2 0}$ & $36(6.0)$ & $4(11.11)$ & $56(9.33)$ & $4(7.14)$ & $92(15.33)$ & $8(8.69)$ \\
\hline $21-30$ & $58(9.67)$ & $10(17.24)$ & $78(13.0)$ & $6(7.69)$ & $136(22.67)$ & $16(11.76)$ \\
\hline $31-40$ & $78(13.0)$ & $5(6.41)$ & $71(11.83)$ & $4(5.63)$ & $149(24.83)$ & $9(6.04)$ \\
\hline $41-50$ & $62(10.33)$ & $1(1.61)$ & $57(9.5)$ & $0(0.0)$ & 119 (19.83) & $2(1.68)$ \\
\hline$\geq 51$ & $75(12.5)$ & $2(2.66)$ & $29(4.83)$ & $0(0.0)$ & $104(17.33)$ & $1(0.96)$ \\
\hline Total & $309(51.5)$ & $22(7.12)$ & $291(48.50)$ & $14(4.8)$ & $600(100.0)$ & $36(6.0)$ \\
\hline
\end{tabular}

${ }^{\mathrm{a}}$ Values are expressed as No. (\%)

no statistical significance was recorded in co-infection between both genders $(\mathrm{P}<0.01)$. The highest rate of infection was recorded among the 21 - 30 year age range with 14 (10.3\%), while males within this age group were also more infected than the female counterparts within the same age range with $9(5.51 \%)$ and $5(6.40 \%)$ rates of infection for male and female, respectively. With a P value of $0.002(<0.05)$, there was a significant difference between the age groups.

\subsection{Infection According to Sampling Location}

Out of the three (3) studied hospitals, the highest rate of co-infection was recorded in BMSH with 14 (7.0\%) (Table 4 ); the analysis also showed that males were more infected than their female counterparts with 9 (7.50\%) and 5 (6.25\%) rate of infection, respectively. This was followed by the military hospital with a prevalence rate of $4.0 \%$ as just 8 subjects were co-infected, males 5 (4.27\%) and females 3 (3.61\%). The lowest rate of co-infection was seen in the Obio Cottage Hospital with just $4(2.0 \%)$ rate of infection; male and female genders having 2 (2.77) and 2 (1.56) infection rate, respectively. The infection rate between the three hospitals were significant with $\mathrm{P}=0.047(\mathrm{P}<0.05)$.

Malaria was higher in BMSH 93 (46.5\%), followed by the Obio Cottage Hospital 81 (40.5\%) while the least amount of infection was recorded in the military hospital 72 (36.0\%), as shown in Table 5. Analysis indicated that female gender in each of the sampling locations were more infected than their male counterparts; $42.96 \%$ females to $36.11 \%$ males in Obio Cottage, $51.25 \%$ females to $43.33 \%$ males in BMSH, and $40.96 \%$ females to $32.47 \%$ males in military hospital. The infection rate between the three hospitals were not significant with $\mathrm{P}=0.101(\mathrm{P}>0.05)$.

HBV infection was also higher in BMSH 17 (8.5\%), followed by military hospital 14 (7.0\%), while Obio Cottage Hospital recorded the least infection rate of 5 (2.5\%) (Table 6). Infection with $\mathrm{HBV}$ in each of the sampling locations was found to show a statistical significance with $\mathrm{P}=0.0369$ $(\mathrm{P}<0.05)$. Males were more infected in both BMSH 11 (9.16\%) and military hospital 9 (7.69\%) than the female gender with $6(7.5 \%)$ and $5(6.02 \%)$, respectively in both hospitals, while Obio Cottage hospital recorded slightly higher prevalence of $3(2.34 \%)$ in females than in males 2 (2.77). The infection rate between the male and female gender indicated no statistical difference $(P>0.05)$.

\section{Discussion}

The result and findings of this present study showed that malaria and HBV infection are prevalent in Port Harcourt and hence continues to be a serious health issue. 


\begin{tabular}{|c|c|c|c|c|c|c|}
\hline \multirow{2}{*}{ Age, $y$} & \multicolumn{2}{|c|}{ Males } & \multicolumn{2}{|c|}{ Females } & \multicolumn{2}{|c|}{ Total } \\
\hline & Examined & Infected & Examined & Infected & Examined & Infected \\
\hline$\leq \mathbf{2 0}$ & $36(6.0)$ & $3(8.33)$ & $56(9.33)$ & $1(1.78)$ & $92(15.33)$ & $4(4.35)$ \\
\hline $21-30$ & $58(9.67)$ & $9(5.51)$ & $78(13.0)$ & $5(6.41)$ & $136(22.67)$ & $14(10.3)$ \\
\hline 41 - 50 & $62(10.33)$ & $1(1.61)$ & $57(9.5)$ & $1(1.75)$ & $119(19.83)$ & $2(1.7)$ \\
\hline$\geq 51$ & $75(12.5)$ & $1(1.33)$ & $29(4.83)$ & $0(0.0)$ & $104(17.33)$ & $1(0.96)$ \\
\hline Total & $309(51.5)$ & $16(5.18)$ & $291(48.50)$ & $10(3.44)$ & $600(100.0)$ & $26(4.33)$ \\
\hline
\end{tabular}

${ }^{\mathrm{a}}$ Values are expressed as No. (\%).

\begin{tabular}{|c|c|c|c|c|c|c|}
\hline \multirow{2}{*}{ Hospitals } & \multicolumn{2}{|c|}{ Males } & \multicolumn{2}{|c|}{ Females } & \multicolumn{2}{|c|}{ Total } \\
\hline & No. Examined & Co-Infected & No. Examined & Co-Infected & No. Examined & Co-Infected \\
\hline Obio Cottage & 72 & $2(2.77)$ & 128 & $2(1.56)$ & 200 & $4(2)$ \\
\hline BMSH & 120 & $9(7.50)$ & 80 & $5(6.25)$ & 200 & $14(7)$ \\
\hline Military & 117 & $5(4.27)$ & 83 & $3(3.61)$ & 200 & $8(4)$ \\
\hline Total & 309 & $16(5.18)$ & $291(48.50)$ & $130(44.67)$ & $600(100.0)$ & $26(4.33)$ \\
\hline
\end{tabular}

${ }^{\mathrm{a}}$ Values are expressed as No. (\%).

\begin{tabular}{|c|c|c|c|c|c|c|}
\hline \multirow{2}{*}{ Hospitals } & \multicolumn{2}{|c|}{ Males } & \multicolumn{2}{|c|}{ Females } & \multicolumn{2}{|c|}{ Total } \\
\hline & No. Examined & Infected & No. Examined & Infected & No. Examined & Infected \\
\hline Obio Cottage & 72 & $26(36.11)$ & 128 & $55(42.96)$ & 200 & $81(40.5)$ \\
\hline BMSH & 120 & $52(43.33)$ & 80 & $41(51.25)$ & 200 & $93(46.5)$ \\
\hline Military & 117 & $38(32.47)$ & 83 & $34(40.96)$ & 200 & $72(36.0)$ \\
\hline Total & $309(51.5)$ & $116(37.54)$ & $291(48.50)$ & $130(44.67)$ & $600(100.0)$ & $246(41.0)$ \\
\hline
\end{tabular}

${ }^{\mathrm{a}}$ Values are expressed as No. (\%).

\begin{tabular}{|c|c|c|c|c|c|c|}
\hline \multirow{2}{*}{ Hospitals } & \multicolumn{2}{|c|}{ Males } & \multicolumn{2}{|c|}{ Females } & \multicolumn{2}{|c|}{ Total } \\
\hline & No. Examined & Infected & No. Examined & Infected & No. Examined & Infected \\
\hline Obio Cottage & 72 & $2(2.77)$ & 128 & $3(2.34)$ & 200 & $5(2.5)$ \\
\hline BMSH & 120 & $11(9.16)$ & 80 & $6(7.5)$ & 200 & $17(8.5)$ \\
\hline Military & 117 & $9(7.69)$ & 83 & $5(6.02)$ & 200 & $14(7.0)$ \\
\hline Total & $309(51.5)$ & $22(7.12)$ & $291(48.50)$ & $14(4.8)$ & $600(100.0)$ & $36(6.0)$ \\
\hline
\end{tabular}

${ }^{\mathrm{a}}$ Values are expressed as No. (\%).

This study revealed a relatively high prevalence rate of $41.0 \%$ for malaria among the sampled subjects in Port Harcourt. The $41.0 \%$ malaria prevalence recorded in this research is less than $78.7 \%$ reported among patients attending the Health Centre of the Federal University of Technology, Akure (FUTA) (13), as well as $80.40 \%$ and $62.7 \%$ re- ported from Aba and Umuahia, respectively $(14,15)$. Although lower prevalence malaria rates had been reported in other researches across several parts of Nigeria $(7,16,17)$, the prevalence recorded in this work is similar to $39.5 \%$ reported among patients visiting a semi-urban based hospital in Nigeria (18). 
The difference and variations in malaria prevalence rate recorded across different parts of the country could be a difference in climatic as well as atmospheric conditions at a particular time across the nation, which could either favor or dis-favor the breeding of mosquitoes (19). The relatively higher prevalence of malaria observed in this research study could be due to the facts that malaria is already a serious endemic issue in Nigeria, as well as the fact that the poor environmental conditions in Port Harcourt favors the breeding and emerging of mosquitoes, the vector of malaria. This study span was between July to December, which is the period of intense rain, hence stagnant water, which serves as good breeding sites for the mosquito vectors. In addition, Port Harcourt and its environment is poorly drained, gutters and other drainage systems are most times filled with waste due to inadequate and poor waste disposal system, and all these provide good sites for the breeding and emerging of mosquitoes, thereby helping in continuous transmission of malaria (20).

Analysis of the results also pointed to the facts that the female gender was more infected with malaria than their male counterparts, with a $44.67 \%$ infection rate. Similar reports were documented by different studies across the country (7, 13-15), however, this contradicts the higher malaria prevalence in males reported in other studies (17, 18). The higher malaria infection rate observed in females could be due to high vulnerability and susceptibility of women to malaria, especially during pregnancy (7). Moreover, the extent of exposure to their environment could also be a contributing factor since females are in constant contact with their immediate surrounding and are more likely to be stable for mosquito bites through their daily activities.

The study also showed that the highest rate of malaria infection was observed in subjects in the 21 - 30 year age range (55.66\%). This agrees with the finding of some earlier work $(7,14,17)$ who reported a higher malaria prevalence among the same age group and contrary to reports $(13,18)$ where age group 1 - 10 years had the highest malaria infection rate. We had a larger population of people within this age group who took part in the study; in addition, it's been observed by WHO findings that young people living in malaria endemic zones are more vulnerable and prone to infection with malaria than the elder ones (21). The higher level of occurrence recorded among this age group could also be due to the extent of exposure to their environment. Though every age group showed susceptibility to malaria infection, the variances in infection rate could be ascribed to differences in lifestyles as well as habits of various age groups. The least malaria infection was documented among the older age groups and similar report was shown in Akure and Gboko $(13,18)$. The lower prevalence of infection recorded among the older age group could be ascribed to the acquired immunity in adults due to previous exposure to malaria infections (22).

This result revealed Plasmodium falciparum as the only diagnosed species of malaria parasite recorded during the course of the study. This agrees with some earlier works $(13,17,18)$, more so, according to WHO, Plasmodium falciparum remains the most common and the principal cause of malaria among the four human malaria parasites across the Sub-Saharan Africa (the three other species includes; $P$. vivax, P. malariae, and P. ovale)(21).

The study also documented a prevalence rate of $6.0 \%$ for HBsAg, which is contrary to $19.0 \%$ reported from Ilorin (8), but is consistent with a $6.5 \%$ and $5.1 \%$ prevalence rate reported from the North and South, respectively $(7,16)$. The finding here is in line with the assertion that HBV infection is on the alarming increase (23) with the prevalence ranging from $3.9 \%$ to $50.7 \%$.

Infection was higher among the 21 - 30 year age group. This is similar to the documented research reports $(7,16)$, which indicated high infection rates of HBV within the same age group. These age groups are more vulnerable to infection with HBV because they make up the bulk of the sexually active and reactive population among the subjects; they are also at a high risk of getting involved in several activities through which the infection can be contracted such as tattooing and illicit use of drugs.

The male populations were detected to have higher infection rates of $7.12 \%$, than females (4.8\%). This corresponds with earlier work $(7,16,23)$, which reported higher infection rates of HBV among the males than the females. The higher rates of the disease observed in the males can be ascribed to unequal exposure to the risk factors predisposing people to the infection. Male populations are often involved in more risk habits, which predisposes them to HBV infection, while the female counterparts are most times under the watch of guardian.

The prevalence and occurrence of co-infection of malaria and hepatitis B virus in the research work was detected to be $4.33 \%$. This, to our judgment, is relatively high; although it is lower than $40.67 \%$ reported by Aernan et al. (5), but higher than $1.9 \%$ reported by Wokem and Amacree (16). The results of this work agree with the 4.5\% co-infection rate reported by Dabo et al. (7). Individual prevalence of either of the infections could be a contributing factor to the co-infection rate witnessed in the study since infection with either of the pathogens could have resulted in suppressed immunity, thereby, creating chances for infection with the other as observed for HIV/Malaria coinfection (24). 
The male population had higher co-infection rates (5.18\%) than the females (3.44\%). This agrees with earlier researchers $(5,7,16)$, in which all reported higher coinfection rates among the male population than the female population. However, no particular reason(s) could be ascribed to this disparity, as this appears to be a worldwide trend.

The youthful age ranges of 21 - 30 years were noted to have higher co-infection rates, similar observation has been documented $(5,7,16)$. This population is involved in higher risk behaviors such as incessant sexual activities, abuse of drugs, and skin piercing, which predisposes them to infections with HBV.

\subsection{Conclusions}

Prevalence of Malaria, HBV, and their co-infection is relatively high in Port Harcourt and suggests that awareness campaign should be intensified among all and sundry so as to prevent further escalation of an already bad case to avoid public health emergency.

\section{Footnotes}

Authors' Contribution: Both author designed, collected and analyzed samples, wrote, and approved manuscript.

Conflict of Interests: The authors declare that there is no conflict of interests.

Ethical Approval: Approval was obtained from the Research Ethics Committee of the University of Port Harcourt, authorities of the Hospitals and written and verbal consent from patients.

Funding/Support: No funding from any source (personal research).

\section{References}

1. Lawn SD. AIDS in Africa: The impact of coinfections on the pathogenesis of HIV-1 infection. J Infect. 2004;48(1):1-12. doi: 10.1016/j.jinf.2003.09.001. [PubMed: 14667787].

2. World Health Organization. World malaria report fact sheet. 2014. Available from: www.who.int/malaria/pubication/world-malaria-report2014/en/.

3. World Health Organization. A global strategy for malaria control, Geneva. 2010. Available from: www.who.int/malaria/publication/ media/world-malaria-report-2010/en.

4. World Health Organization. Anonymous global distribution of hepatitis A, $B$ and C. Weekly epidemiological record. $2002.2 \mathrm{p}$.

5. Aernan PT, Sar TT, Torkula SH. Prevalence of Plasmodia and hepatitis $B$ virus co-infection in blood donors at Bishop Murray Medical Centre, Makurdi, Benue State, Nigeria. Asian Pac J Trop Med. 2011;4(3):2246. doi:10.1016/S1995-7645(11)60074-6. [PubMed: 21771458]
6. Andrade BB, Santos CJ, Camargo LM, Souza-Neto SM, Reis-Filho A, Clarencio J, et al. Hepatitis B infection is associated with asymptomatic malaria in the Brazilian Amazon. PLoS One. 2011;6(5). e19841. doi: 10.1371/journal.pone.0019841. [PubMed: 21625634]. [PubMed Central: PMC3097216].

7. Dabo NT, Sharif AA, Muhammed Y, Sarkinfada F. Malaria and hepatitis B co-infection in patients with febrile illnesses attending general outpatient unit of the Murtala Muhammed Specialist Hospital, Kano, Northwest Nigeria. Bayero J Pure Appl Sci. 2015;8(1):89-95. doi: 10.4314/bajopas.v811.16.

8. Kolawole OM, Kana SN. Hepatitis B virus and malaria Co-infection causing significant changes in hematological and liver function indices in a cohort of subjects in Ilorin, Nigeria. Int JInfect. 2018;5(3). doi: 10.5812/iji.81528.

9. Kish L. Survey Samping. New Jersey, United States: John Wiley and Sons; 1965. p. 50-3.

10. Ebong A. Remote sensing and GIS. Nigeria: Nigerian Defence Academy; 2019. 24 p.

11. Cheesbrough M. District laboratory practice in tropical countries. Cambridge: Cambridge University Press; 2005. p. 239-45. doi: 10.1017/cbo9780511581304.

12. Blumberg BS, Sutnick AI, London WT, Millman I. The discovery of Australia antigen and its relation to viral hepatitis. Vitro. 1971;7:223.

13. Obimakinde E, Simon-Oke I. The prevalence of malaria infection among patients attending the health centre of the Federal University of Technology, Akure, Nigeria. Int J Trop Dis Health. 2017;27(4):1-7. doi: 10.9734/ijtdh/2017/35340.

14. Mong Kalu K, Ajuka Obas N, Onyemachi F, Otuchristi G. A comparative study of the prevalence of malaria in Aba and Umuahia Urban areas of Abia State, Nigeria. Res J Parasitol. 2012;7(1):17-24. doi: 10.3923/jp.2012.17.24.

15. Olasehinde GI, Ojurongbe DO, Akinjogunl OJ, Egwari LO, Adeyeba AO. Prevalence of malaria and predisposing factors to antimalarial drug resistance in Southwestern Nigeria. Res J Parasitol. 2015;10(3):92-101. doi: 10.3923/jp.2015.92.101.

16. Wokem GN, Amacree MA. Malaria and hepatitis B co-infection in relation to selected haematological parameters among attendees of two health facilities in Port Harcourt, Nigeria. Int J Appl Sci Res Rev. 2018;5(10):54. doi: 10.21767/2394-9988-C2-006.

17. Abah AE, Joe-Cliff O. Current status of malaria parasite among blood donors in Port Harcourt, Rivers State, Nigeria. J Appl Sci Environ Manage. 2016;20(1):187. doi: 10.4314/jasem.v20i1.22.

18. Houmsou RS, Amuta EU, Sar TT, Adagba AH. Malarial infection among patients attending a Nigerian semi-urban based hospital and performance of HRP-2 pf rapid diagnostic test (RDT) in screening clinical cases of Plasmodium falciparum malaria. Transl Res Biomed. 2011;2(1).

19. Mordi RM, Borke ME. The prevalence of malaria in Edo State, Nigeria. Nig J Parasitol. 2013;34(2):41-6.

20. Chandler AC, Read CP. Introduction to parasitology. 10th ed. New York, USA: John Wiley and Sons Inc; 2001. 822 p.

21. World Health Organization. African malaria report. Geneva; 2003.

22. Kamwi RN, Mfune JKE, Kaaya GP, Jonazi JB. Seasonal variation in the prevalence of malaria and vector species in Northern Namibia.J Entomol Nematol. 2012;4(5):42-8

23. Aminu M, Vandu MD. Hepatitis B infection in Nigeria: A review. The 4th Unibadan Conference of Biomedical Research. Ibadan, Nigeria. 2014. p.1-4.

24. Louie JK, Lampiris HW. Infection and travel in patients with HIV disease. 2004. Available from: http://hivinsite.ucsf.edu/insite? 